\title{
Clinico-Pathological Conference on Acute Kidney Injury in a Patient with Nephrotic Syndrome
}

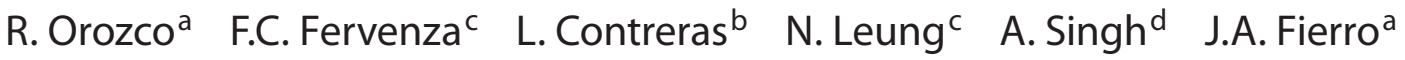 \\ a Division of Nephrology and Hypertension, and bepartment of Pathology, Clinica Las Condes, Santiago, Chile; \\ 'Division of Nephrology and Hypertension, Mayo Clinic, Rochester, Minn., and ${ }^{\mathrm{d}}$ Renal Division, Brigham and \\ Women's Hospital, Harvard Medical School, Boston, Mass., USA
}

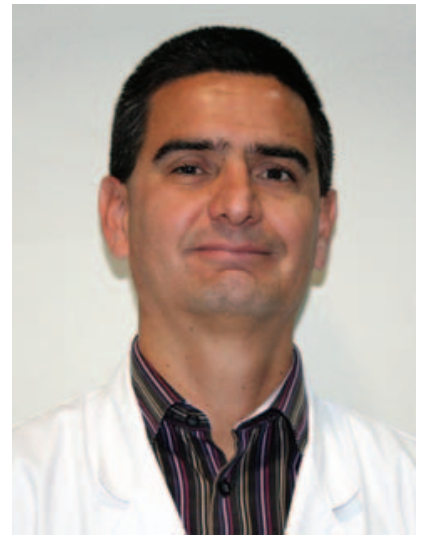

\section{Biography}

Rodrigo Orozco, 43 years old, graduated (1992) in Medicine from Universidad de Chile in Santiago de Chile.

He went on to complete his residence in internal medicine (1992-1995) and nephrology (1995-1997) at Pontificia Universidad Catolica de Chile in Santiago de Chile. $\mathrm{He}$ entered a postgraduate program in Nephrology at Hôpital Necker, Paris, from 1998 to 1999. Dr. Orozco is currently Head of the Dialysis Unit at Clinica Las Condes in Santiago de Chile.

\section{KARGER}

Fax +41613061234 E-Mail karger@karger.ch www.karger.com

\section{Case Presentation}

Dr. Orozco: The patient is a 57 -year-old female patient who presented to the emergency room with rapid onset of lower extremity edema. She denied any other systemic symptoms. Her past medical history was significant for vascular headaches and springtime allergies. Medications included calcium, vitamin D supplementation and desloratadine. Physical examination revealed a healthy-looking woman in no apparent distress. Her blood pressure was $140 / 90 \mathrm{~mm} \mathrm{Hg}$, heart rate 80 per min and a temperature of $37^{\circ} \mathrm{C}$. The remainder of the examination was unremarkable, except for 2++ edema in the lower extremities. Laboratory evaluation was as follows: urinalysis showed specific gravity $1,030, \mathrm{pH} 6.0$, blood ++, albumin +++. Urine microscopy showed: 70 red blood cells/high-power field (RBCs/HPF), few hyaline casts and several fat droplets but no cellular casts. The urine albumin-to-creatinine ratio was high: 12,468 (normal value $<30$ ). Electrolytes were within the normal range, Blood urea nitrogen was $28 \mathrm{mg} / \mathrm{dl}$, serum creatinine was $0.9 \mathrm{mg} / \mathrm{dl}(80 \mu \mathrm{mol} / \mathrm{l})$, corresponding to an estimated glomerular filtration rate of $60 \mathrm{ml} /$ $\min / 1.73 \mathrm{~m}^{2}$ by the four-variable Modification of Diet in Renal Disease (MDRD) equation. A serum creatinine test taken 3 months earlier was $0.74 \mathrm{mg} / \mathrm{dl}(65 \mu \mathrm{mol} / \mathrm{l})$. The hemoglobin was $13 \mathrm{~g} / \mathrm{dl}$, leukocyte count was $13,960 / \mu \mathrm{l}$, platelet count was 150,000 and erythrocyte sedimentation rate was $18 \mathrm{~mm} / \mathrm{h}$. Liver function tests were all normal. Serum albumin was $2.5 \mathrm{~g} / \mathrm{dl}$, total cholesterol was $279 \mathrm{mg} / \mathrm{dl}(7.3 \mathrm{mmol} / \mathrm{l})$ with an LDL cholesterol concentration of $213 \mathrm{mg} / \mathrm{dl}(5.5 \mathrm{mmol} / \mathrm{l}$; normal value $<130 \mathrm{mg} / \mathrm{dl}$ or 3.3 $\mathrm{mmol} / \mathrm{l}$ ). D-dimer concentration was elevated at $3.75 \mu \mathrm{g} / \mathrm{ml}$ (normal value $<0.5 \mu \mathrm{g} / \mathrm{ml}$ ). Immunologic data showed an antinuclear antibody titer of $1 / 40$. Results of antineutrophil cytoplasmic antibodies, anti-double-stranded DNA antibodies, $\mathrm{C} 3 / \mathrm{C} 4$ comple- 
Fig. 1. Angiographic reconstruction of a contrast-enhanced CT, showing signs of a thrombus in the left renal vein (arrows).
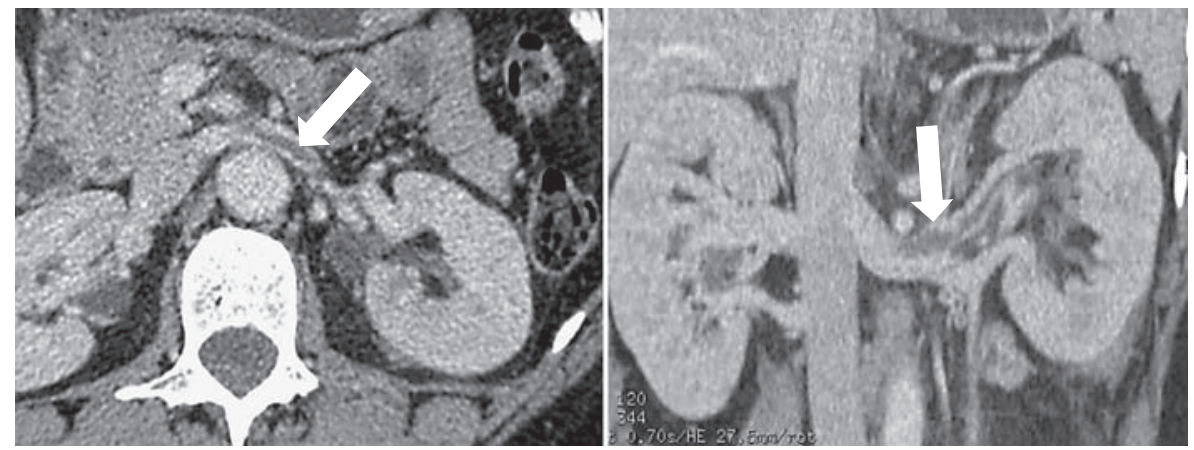

ment levels, anticardiolipins antibodies, hepatitis B, C, and HIV serology, as well as serum and urine monoclonal protein evaluation were all negative or in the normal range. Chest radiography was normal and Doppler ultrasound of the lower extremities revealed no deep-vein thrombosis (DVT). Abdominal ultrasound showed normal-size kidneys, with no evidence for masses or hydronephrosis. To further evaluate the cause of the nephrotic syndrome, a renal biopsy was performed.

\section{Discussion}

Dr. Singh: I would like to invite Dr. Fernando Fervenza and Dr. Nelson Leung to discuss this patient's presentation.

Dr. Fervenza: Dr. Leung, could you please comment on the differential diagnosis for this patient?

Dr. Leung: The differential diagnosis of this patient comprises of common causes of severe nephrotic syndrome, such as membranous nephropathy, focal and segmental glomerulosclerosis, and minimal-change disease. I also think of amyloidosis as part of this group. Membranoproliferative glomerulonephritis is also part of the differential diagnosis, although normal serum complement levels, negative hepatitis C serology and the absence of circulating monoclonal protein make this diagnosis unlikely.

Dr. Fervenza: Dr. Orozco, you said there were numerous red cells on urine microscopy.

Dr. Orozco: Yes, you are right. There were 70 RBCs/ HPF.

Dr. Fervenza: Dr. Leung, does the fact that there was significant hematuria and proteinuria change your differential diagnosis? Also, the evaluation for monoclonal proteins was negative, both in plasma and urine. Do you still think amyloidosis remains a possible diagnosis?

Acute Kidney Injury in a Patient with Nephrotic Syndrome
Dr. Leung: We could also consider lupus nephritis, but the immunological panel is negative. IgA nephropathy (IgAN) would certainly also be possible, although proteinuria of $12 \mathrm{~g} / 24 \mathrm{~h}$ is very unusual for IgAN alone. However, IgAN could occur along with severe podocytopathy. In my mind, amyloidosis remains a possibility because approximately $5 \%$ of patients with immunoglobulin light-chain amyloidosis are negative by serum and urine immunofixation. As well, AA (which is also known as secondary amyloidosis) and hereditary forms of amyloidosis do not have a monoclonal protein. Thus, immunofixation would be negative.

Dr. Morales: Dr. Orozco, why were laboratory tests performed 3 months before the patient presented to you?

Dr. Orozco: She was evaluated because of headaches. These headaches were attributed to a vasomotor cause. During the current admission, and 3 days after her renal biopsy, persistent headaches led us to obtain a head CT and magnetic resonance evaluation; both were normal. At that time, a contrast-enhanced CT of the abdomen and thorax was also performed and showed thrombosis of the left renal vein (fig. 1); there was also an embolus in the right lower pulmonary lobe. The patient was then started on anticoagulation therapy with low-molecular-weight heparin.

Dr. Fervenza: Were you concerned about anticoagulating this patient 3 days after a renal biopsy?

Dr. Orozco: Yes, but the patient had no complication or hematoma on the CT. I want to comment also that at the beginning the patient had elevated D-dimer concentrations and was nephrotic. Interestingly, the initial search for a DVT was negative.

Dr. Fervenza: What would have been your approach if renal vein thrombosis had been detected before you performed the kidney biopsy? Would you have done the biopsy or would you have initiated anticoagulation first, and delayed the biopsy?

Nephron Clin Pract 2011;119:c240-c247 

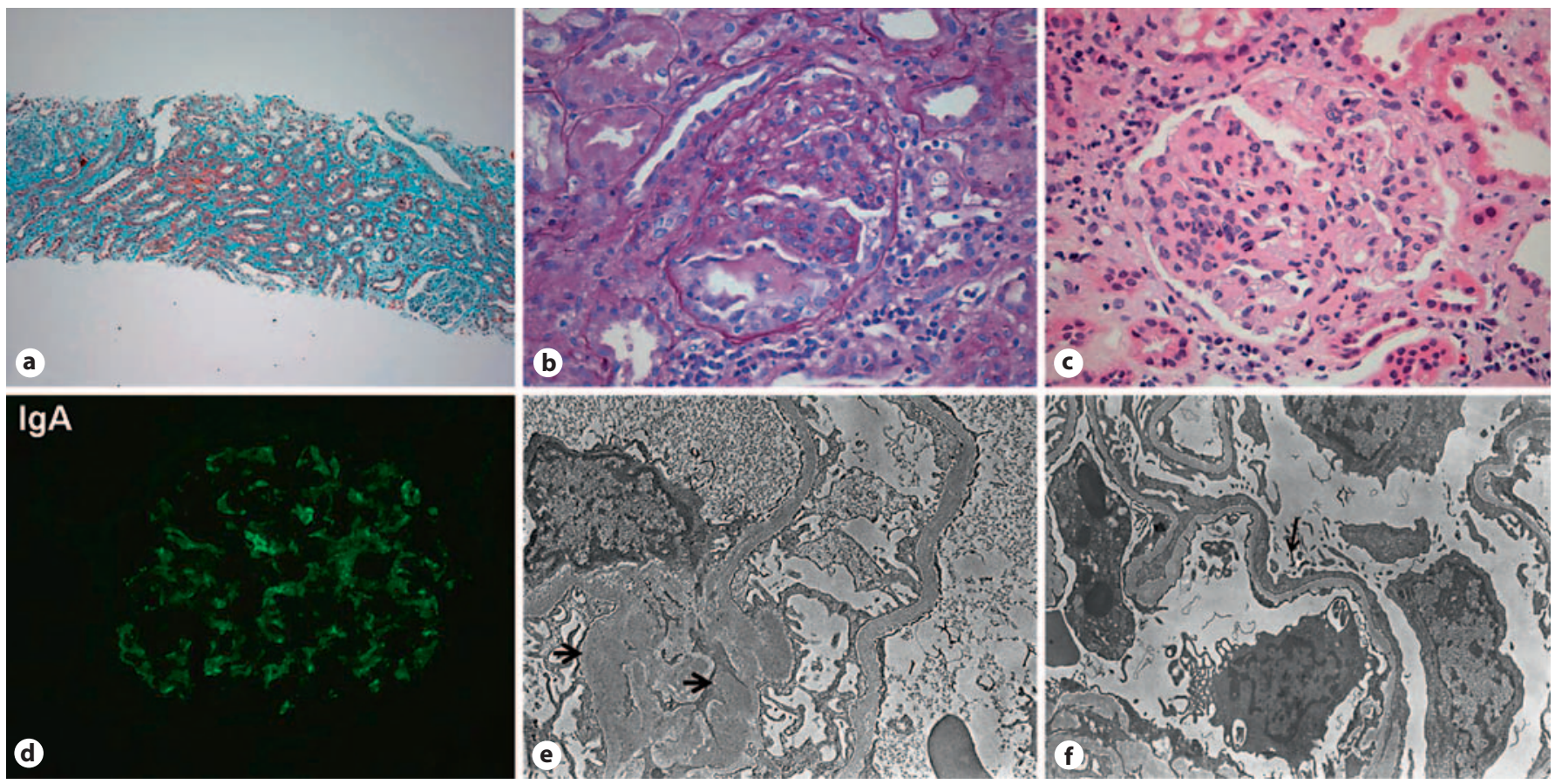

Fig. 2. The first kidney biopsy shows important mesangial and glomerular endocapillary proliferation on light microscopy. a-c There was only minor interstitial fibrosis. Epithelial crescents were present in $20 \%$ of the glomeruli. $\mathbf{d}$ Immunofluorescence is positive for IgA. e, $\mathbf{f}$ Electron microscopy shows electron-dense deposits in the mesangium, and widespread foot process effacement. The diagnosis is consistent with IgAN, class IV in the Haas classification with diffuse podocyte damage.

Dr. Orozco: If there was no evidence of embolization, I would still have performed the biopsy first and then started anticoagulation.

Dr. Fervenza: In my opinion, the presence of thrombi in the context of severe nephrotic syndrome poses an interesting management dilemma. Because of the presence of a DVT, or renal vein thrombosis, I would have anticoagulated the patient first and delayed the biopsy until the clot was stable (for example, a delay of 3 months). In the presence of a DVT or renal vein thrombosis, there is a great risk of developing pulmonary emboli, which in fact occurred in this patient, and can be associated with significant morbidity/mortality. Under these circumstances, I believe the priority should be the patient's life rather than the diagnosis.

Dr. Fervenza: Could we look at the biopsy now?

Dr. Contreras (renal pathologist): On light microscopy, we saw a relatively normal kidney cortex. There was little interstitial fibrosis, but the glomeruli showed important mesangial and endocapillary proliferation. Four of the twenty available glomeruli showed epithelial crescents. Immunofluorescence showed positive staining for IgA,
C3, $\kappa$ and $\lambda$. Electron-microscopic examination showed mesangial electron-dense deposits, with no subendothelial deposits. Diffuse podocyte effacement was present in the free loops. The diagnosis was IgAN (class IV in the Hass classification) [1] with diffuse podocyte damage (fig. 2). We have not adopted the Oxford classification as yet [2,3].

Dr. Fervenza: Dr. Contreras, did you measure the thickness of the glomerular basement membrane?

Dr. Contreras: Yes, but we did not detect thin glomerular basement membrane if that is what you are asking. Thin glomerular basement membrane abnormalities (TBMAs) have been described in approximately $5 \%$ of native kidney biopsies. TBMAs are more common in patients with IgAN and mesangial proliferative glomerulonephritis [4]. In the present case, the width of the podocytes was very similar to the width of the glomerular basement membrane and no evidence of lamellation was seen to suggest an inherited nephropathy.

Dr. Leung: In summary, this patient had IgAN, likely with superimposed minimal-change disease, or minimal-change disease with IgAN in the background. 
Dr. Fervenza: I would say the patient had IgAN with an associated podocytopathy because, strictly speaking, minimal-change disease is defined as the absence of glomerular abnormalities on light microscopy and negative immunofluorescence, which was not the case in this patient. However, it is well recognized that approximately $5 \%$ of the patients with IgAN present with acute-onset nephrotic syndrome, behave clinically as having minimal-change disease, and the prognosis is dictated by the response to corticosteroid therapy [5-7].

Kim et al. [6] performed a retrospective analysis on 581 patients with IgAN and reported that nephrotic syndrome was the initial form of presentation in 48 patients (8.3\%). Twenty-five patients were treated with high-dose corticosteroids. In 12 patients, complete remission of proteinuria was achieved within 2 months from the start of therapy. Electron-microscopic examination showed extensive foot process effacement in 8 patients, while focal effacement was seen in the remaining 4 patients. Similar to patients with minimal-change disease, relapses were frequent but reintroduction of immunosuppression therapy resulted in remission in all cases. The long-term prognosis was excellent and none of these patients progressed to end-stage renal disease (ESRD) [6]. A similar beneficial effect of corticosteroid therapy in $7(40 \%)$ out of 17 patients with IgAN and nephrotic syndrome was reported by Lai et al. [8].

On the other hand, patients who do not respond to corticosteroid therapy are likely to progress to ESRD. In the study by Kim et al. [6] cited above, among 13 patients who did not respond to corticosteroid treatment, $5 \mathrm{pa}-$ tients (38\%) progressed to ESRD. When renal biopsies were graded according to the classification proposed by Lee et al. [9], responders were shown to have mild histological grading (grade I, $\mathrm{n}=3$; grade II, $\mathrm{n}=5$; grade III, $\mathrm{n}=4$; none with grade IV or $\mathrm{V}$ ). In nonresponders, widespread foot process effacement was seen in 2 patients and focal effacement was present in 6 patients [6]. Similarly, in the study by Lai et al. [8], 6 of the 7 patients who responded to corticosteroids had mild glomerular injury.

I think it is important to recognize that IgAN may present as one of several different clinical syndromes; isolated hematuria or proteinuria, nephritic syndrome, and the nephritic syndrome with or without rapidly progressive glomerulonephritis. Our patient presented with sudden onset of nephrotic syndrome (i.e. proteinuria $>3.5 \mathrm{~g} / 24 \mathrm{~h}$ and serum albumin $<3 \mathrm{~g} / \mathrm{dl}$ ), in which renal function is preserved (except in cases of superimposed acute tubular necrosis, ATN). The pathology may show only mild glomerular lesions and/or tubular damage. This presentation needs to be contrasted with a more insidious increase in proteinuria that can reach the nephrotic range, but these patients do not have the nephrotic syndrome. I would say that patients in the first group have an IgAN-associated podocytopathy and are likely to respond to high-dose corticosteroids, while patients in the second group tend to be older, have more severe hypertension, increased serum creatinine and more severe glomerular and tubulointerstitial damage (e.g. concomitant focal segmental glomerulosclerosis with tubular atrophy). This last group is unlikely to benefit from corticosteroid therapy.

Interestingly, a few years ago, I saw a patient who presented with severe nephrotic syndrome, proteinuria of $7 \mathrm{~g} / 24 \mathrm{~h}$ and a serum creatinine of $5 \mathrm{mg} / \mathrm{dl}$, and the renal biopsy showed IgAN, $100 \%$ podocyte effacement, ATN, and on top of this, the patient also had TBMA. The patient was treated with high-dose corticosteroids and went into complete remission. One year later he relapsed with proteinuria going up to $12 \mathrm{~g} / 24 \mathrm{~h}$ and again he went into acute renal failure. He underwent a repeat renal biopsy that showed exactly the same findings as seen in the first biopsy.

Dr. Contreras: I wonder if we could advance a hypothesis about the mechanisms that allow that a predominantly mesangial disease such as IgAN could suddenly present with nephrotic syndrome and behave like minimal change disease (MCD), which reflects a podocytopathy?

Dr. Fierro: One of the main facts in IgAN is the deposition of IgA-containing immune complexes in the mesangium. The deposition of immune complexes induces inflammation. This occurs either by direct activation of the complement system, by activation of specific receptors or by being the target of an IgG anti-IgA. Whatever the mechanism, these immune complexes induce inflammation, could disrupt the basal membrane and affect the podocytes. However, I do not think that this is the mechanism in patients who present with sudden onset of nephrotic syndrome and who rapidly respond to corticosteroids as a patient with MCD. My guess is they are coincidental processes. Just because a patient has IgAN does not prevent him from developing MCD. In fact, in a number of cases of recurrent nephrotic syndrome in which sequential renal biopsies were performed, initial biopsy showed MCD, not IgAN [10]. However, subsequent biopsies showed IgAN. The concept of two diseases coexisting together is an important one because, as discussed by Dr. Fervenza, management is different. 

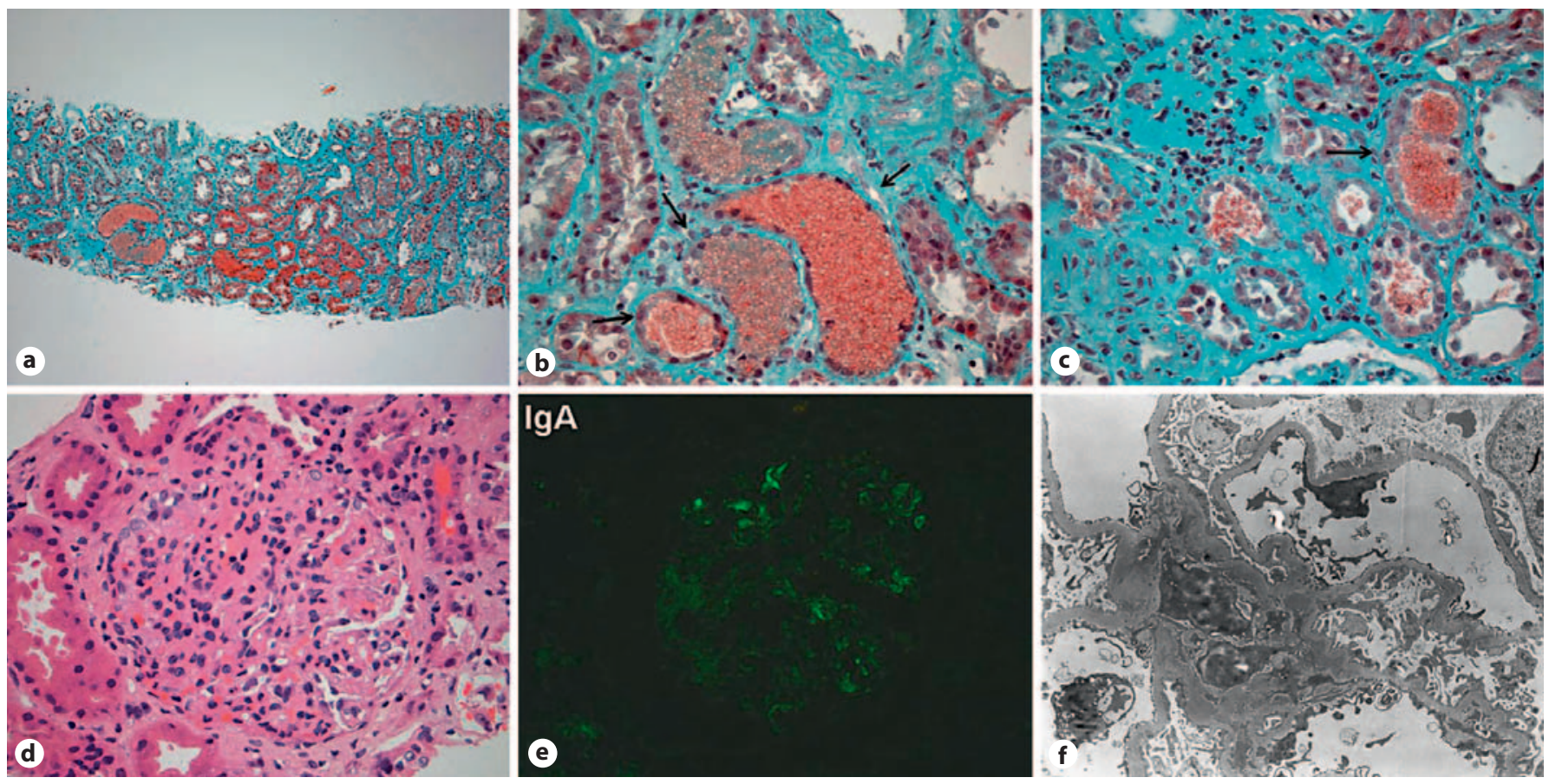

Fig. 3. a-c The second biopsy demonstrates multiple red cell casts within the renal tubules as well as areas of acute tubular necrosis. d Glomerular crescents were also present. Immunofluorescence shows persistence of IgA (e) and the electron microscopy (f) shows slightly less foot process effacement.

Dr. Orozco: As discussed previously, nephrotic syndrome is uncommon ( $<5 \%$ of all cases) in patients with IgAN and is more commonly seen in children and adolescents [11]. Based on the findings on the renal biopsy, the patient was started on prednisone $(1 \mathrm{mg} / \mathrm{kg} / \mathrm{day}$, orally). However, 14 days after the start of corticosteroid therapy, she returned to the clinic feeling unwell, complaining of lack of energy, anorexia, bilateral flank pain, and macroscopic hematuria. Her creatinine had risen to $4.5 \mathrm{mg} / \mathrm{dl}$ (398 $\mu \mathrm{mol} / \mathrm{l}$ ) corresponding to an MDRD calculated clearance of $8 \mathrm{ml} / \mathrm{min}$. There was no history to suggest dehydration (e.g. no vomiting or diarrhea) nor had the patient been taking any nephrotoxic medication. She was treated with 3 pulses of methylprednisolone, $500 \mathrm{mg}$ each, intravenously, and due to the uncertainty of the cause of her acute renal failure a second renal biopsy was performed.

Dr. Espinoza: Did you consider that she could have thrombosed both renal veins?

Dr. Orozco: Yes, but we found this unlikely. Following the initial treatment with low-molecular-weight heparin the patient had been converted to oral anticoagulation with warfarin and at the time of her second presentation her international normalized ratio (INR) was 3.0.
Dr. Fierro: Despite steroid treatment, the patient presented with acute kidney injury superimposed on heavy proteinuria and hematuria. The clinical presentation had changed and the differential diagnosis is worthy of discussion. We considered the possibility of ATN, but the presence of crescents in the first biopsy also prompted us to consider the possibility of a crescentic glomerulonephritis. Back in the 1980s, Bennett and Kincaid-Smith [12] conducted a study correlating macroscopic hematuria, glomerular crescents and renal dysfunction in patients with IgAN. They looked at 186 renal biopsies from 79 adult patients with IgAN and divided the patients in either those with a history of macroscopic hematuria (group 1; $\mathrm{n}=40$ ) or those without such a history (group $2 ; \mathrm{n}=39$ ). Patients in group 1 had higher serum creatinine and lower creatinine clearance than patients in group 2 . Fourteen biopsies were performed in 11 patients during an episode of macroscopic hematuria and all showed crescents (100\%). In the 10 patients who underwent renal biopsy 3-27 days following an episode of macroscopic hematuria but still had $>10^{6} \mathrm{RBCs} / \mathrm{ml}$ in the urine $\left(10^{5}-10^{6}\right.$ $\mathrm{RBCs} / \mathrm{ml} \sim 20 \mathrm{RBCs} / \mathrm{HPF}$ ), crescents were present in $91 \%$ of the cases. Similarly, of the 13 patients without a history 
of macroscopic hematuria but with $>10^{6} \mathrm{RBCs} / \mathrm{ml}$ in the urine, $79 \%$ had crescents on the biopsy. This all tells us that in patients with IgAN, heavy or macroscopic hematuria is associated with a high likelihood of crescents on renal biopsy and worsening renal function. It was important for us to determine the precise diagnosis because if the biopsy showed ATN, then treatment would be largely supportive. On the other hand, if the kidney biopsy showed an active crescentic glomerulonephritis, we could consider treating with cyclophosphamide or even plasmapheresis, although this last form of treatment has been controversial in patients with IgAN.

Dr. Contreras: The second biopsy again showed IgAN, but this time we found plenty of red blood cell casts in the tubules, as well as clear signs of ATN. Immunofluorescence examination showed similar findings to the first biopsy. Electron microscopy examination showed a slightly lesser degree of podocyte fusion in comparison to the first biopsy (fig. 3).

Dr. Fervenza: Dr. Contreras, what happened to the crescents? Have they progressed, improved or shown no changes?

Dr. Contreras: The crescents in the second biopsy showed no changes in comparison with the first biopsy.

Dr. Fervenza: Dr. Orozco, could you comment on the occurrence of ATN in IgAN?

Dr. Orozco: In patients with IgAN, episodes of selflimited recurrent macroscopic hematuria are common, and usually coincide with an episode of respiratory tract infection or bacterial tonsillitis (synpharyngitic hematuria). However, in patients with IgAN, development of acute kidney injury is uncommon ( $<5 \%$ of all cases) [11]. Two mechanisms have been proposed: (1) severe inflammatory injury, e.g. crescentic glomerulonephritis, and (2) ATN resulting from tubular cell injury in patients with heavy hematuria [13-16]. In a study of 244 patients with IgAN, episodes of acute renal failure were observed in 16 patients $[13,14]$. All 16 patients had a history of heavy/macroscopic hematuria. As in the present case, flank pain accompanied the macroscopic hematuria in 10 of these patients. In 13 out of the 16 patients, renal biopsy was done at the time of presentation with acute renal failure and showed crescents in all. As previously discussed, crescents are commonly seen in patients with IgAN, especially in the presence of macroscopic hematuria, but they usually involve less than $25 \%$ of the glomeruli [12].

In all of the 13 patients described above, renal biopsy showed extensive RBCs and red blood cell casts in the tubules as well as morphological changes of ATN, but in only 1 case were the crescents sufficiently widespread to explain the cause of the renal failure [15]. In these cases, acute renal failure has been ascribed to tubular obstruction by red cell casts [17]. However, the most common histological lesion is ATN and the presence of hemoglobin and hemosiderin in the tubular cells $[1,2]$. This suggests that either hemoglobin or the iron released from lysed red cells is responsible for the tubular damages [18]. This form of acute renal failure is generally a benign complication; the serum creatinine concentration most commonly returns to baseline levels within several weeks to months, even if dialysis is temporarily required [13-15]. However, incomplete recovery of renal function has been described in up to $25 \%$ of affected patients [19].

Dr. Fervenza: Intratubular obstruction by heme pigment casts may be directly toxic to proximal tubular cells as the free iron induces oxygen radicals while the heme protein increases the sensitivity to oxygen radicals [20, 21]. It is worth mentioning that hypovolemia and acidosis predispose experimental animals and humans to pigment-induced ATN, since at acid $\mathrm{pH}$, myoglobin and hemoglobin are sources of ferrihemate, a potent inhibitor of tubule transport.

Dr. Fierro: There is a recent report on a patient with macroscopic hematuria and ATN [22]. Renal biopsy showed IgAN with extensive interstitial red blood cell extravasation, hemosiderin deposition, and abundant macrophage infiltration, suggesting a role for free hemoglobin in the pathogenesis of tubulointerstitial injury.

Dr. Contreras: I would say that the present case differs from the one you described because renal biopsy showed only scan mononuclear infiltrate and there was minimal extravasation of red cells in the interstitium.

Dr. Leung: Should this patient have been treated according to the Pozzi protocol?

Dr. Orozco: I would think rather not. The study by Pozzi et al. $[23,24]$ you are referring to was conducted in patients with IgAN who had proteinuria $>1 \mathrm{~g} / 24 \mathrm{~h}$ but $<3.5 \mathrm{~g} / 24 \mathrm{~h}$, thus these patients did not have full-blown nephrotic syndrome as in the present case. In my opinion, patients with IgAN and nephrotic syndrome should be treated as MCD $[8,25]$. In these patients, mesangial IgA deposits often disappear, or are greatly reduced over time [26-28]. On the other hand, nephrotic syndrome can also occur with severe chronic IgAN and relatively advanced disease on renal biopsy. These last patients do not seem to benefit from corticosteroid therapy alone $[8,25]$.

Dr. Fervenza: It is important to emphasize that although it is well known that the majority of patients with IgAN have some degree of proteinuria, and that a number 
of studies have demonstrated that the degree and duration of proteinuria have a strong correlation with prognosis [29-34], and in fact some of the patients included in the studies may have nephrotic-range proteinuria, only a hand full of patients may actually present with nephrotic syndrome. This distinction is important when analyzing studies evaluating effects of immunosuppression therapy in patients with IgAN.

Dr. Fervenza: What happened to the patient? Did renal function improve?

Dr. Orozco: No, her renal function continued to deteriorate. Her nephrotic syndrome also did not improve. Her serum creatinine reached $3.0 \mathrm{mg} / \mathrm{dl}(265 \mu \mathrm{mol} / \mathrm{l})$ and, therefore, we decided to treat her with cyclophosphamide in intravenous pulses. After 5 pulses, her serum creatinine decreased to $1.6 \mathrm{mg} / \mathrm{dl}(140 \mu \mathrm{mol} / \mathrm{l})$. In December 2010, 1 year after the first kidney biopsy, her serum creatinine remained at $1.5 \mathrm{mg} / \mathrm{dl}(132 \mu \mathrm{mol} / \mathrm{l})$, corresponding to an estimated glomerular filtration rate of $35 \mathrm{ml} / \mathrm{min} / 1.73 \mathrm{~m}^{2}$ by the four-variable MDRD equation.

Dr. Singh: What was the rationale to use intravenouspulse cyclophosphamide?

Dr. Orozco: It was based on inference from the antineutrophil cytoplasmic antibody-vasculitis literature showing that intravenous-pulse cyclophosphamide is as effective as oral cyclophosphamide in patients with rapidly progressive glomerulonephritis [35]. The best evidence for the use of cyclophosphamide in IgAN comes from the study by Ballardie and Roberts [36], but they use oral cyclophosphamide combined with prednisolone.

Dr. Fervenza: Dr. Orozco, would you like to comment on the epidemiology of IgAN?

Dr. Orozco: IgAN is considered to be the most common glomerulonephritis in the world. A study conducted in $>50,000$ young to middle-aged Japanese males that were part of a screening program for hematuria and proteinuria showed that about $1.5 \%$ of the participants had abnormal urinary findings, e.g. hematuria and/or proteinuria [37]. When these patients were biopsied for isolated microscopic hematuria, $76 \%$ of them had IgAN, and if biopsied for isolated proteinuria, then $37 \%$ had IgAN. But when patients were biopsied with both, $>90 \%$ had $\operatorname{Ig} A N$. This gives a prevalence of IgAN in Japan of about 1:100 [37]. An interesting point regards the age of presentation of IgAN. The disease is said to present at an early age, but data coming from Australia suggest that this is not the case for males. In a retrospective review of the pathology reports of all native renal biopsies performed in the state of Victoria in 1995 and 1997, IgAN was the most common glomerulonephritis found in adults, and although the age of presentation peaked between 25 and 34 years in females, the same peak was 55-64 years in males [38].

Dr. Singh: Do you have any data regarding the epidemiology of IgAN in Chile?

Dr. Fierro: Yes, there are interesting Chilean data. Dr. Helmar Rosemberg, from the Catholic University in Santiago, examined the prevalence of IgAN in his biopsy material and found that IgAN was the most common glomerulopathy (25\%) [39]. Thus, not only in the US, Europe and Japan but also in Chile is IgAN the most common glomerulopathy found in patients who undergo a kidney biopsy. In the mentioned study, the morphologic features ranged from minimal changes to diffuse sclerosing glomerulonephritis, also including diffuse crescentic glomerulonephritis. Clinical findings at the time of renal biopsy included isolated hematuria in $61 \%$, nephrotic syndrome or proteinuria in $11 \%$, hypertension in $16 \%$, chronic renal failure in 7\%, acute renal failure or nephritic syndrome in $3 \%$ and rapidly progressive glomerulonephritis in $2 \%$. The authors confirmed that IgAN leads to a variety of forms of renal damage, including the less frequent severe crescentic glomerulonephritis.

Dr. Singh: I think that it is important to recognize that a small number of IgAN patients may present with a fullblown nephrotic syndrome. These patients usually have minimal glomerular damage but diffuse foot process effacement on renal biopsy. They are likely to respond to corticosteroids and their long-term prognosis is excellent. On the other hand, as discussed by Dr. Fervenza, there is a second group of patients with IgAN that have nephrotic-range proteinuria but not nephrotic syndrome. These patients usually have impaired kidney function at presentation, and are more likely to be hypertensive. In these patients, the renal biopsy usually shows more severe glomerular and tubulointerstitial damage. Patients in the second group are less likely to benefit from corticosteroid therapy, and their long-term prognosis is poor. The present case also illustrates another unusual presentation in IgAN, and that is of ATN. Usually, these episodes of ATN are self-limited, dialysis is rarely required and renal recovery is the norm, although it has been said that in elderly patients recovery may be more protracted. The current case also raises the management dilemma of how to manage renal vein thrombosis in patients with severe nephritic syndrome. While anticoagulating the patient may interfere with performing a renal biopsy, as Dr. Fervenza discussed, the overall safety of the patient should be our paramount concern. Thank you all for your outstanding case discussion. 


\section{References}

1 Haas M: Histologic subclassification of IgA nephropathy: a clinicopathologic study of 244 cases. Am J Kidney Dis 1997;29:829842.

$\checkmark 2$ Cattran DC, Coppo R, Cook HT, Feehally $\mathrm{J}$, et al: The Oxford classification of IgA nephropathy: rationale, clinicopathological correlations, and classification. Kidney Int 2009;76:534-545.

3 Roberts IS, Cook HT, Troyanov S, Alpers CE, et al: The Oxford classification of IgA nephropathy: pathology definitions, correlations, and reproducibility. Kidney Int 2009; 76:546-556.

4 Cosio FG, Falkenhain ME, Sedmak DD: Association of thin glomerular basement membrane with other glomerulopathies. Kidney Int 1994;46:471-474.

5 Lai KN, Lai FM, Chan KW, Ho CP, et al: An overlapping syndrome of IgA nephropathy and lipoid nephrosis. Am J Clin Pathol 1986; 86:716-723.

6 Kim SM, Moon KC, Oh KH, Joo KW, et al: Clinicopathologic characteristics of IgA nephropathy with steroid-responsive nephrotic syndrome. J Korean Med Sci 2009;24 (suppl):S44-S49.

7 Philibert D, Cattran D, Cook T: Clinicopathologic correlation in IgA nephropathy. Semin Nephrol 2008;28:10-17.

$\checkmark 8$ Lai KN, Lai FM, Ho CP, Chan KW: Corticosteroid therapy in IgA nephropathy with nephrotic syndrome: a long-term controlled trial. Clin Nephrol 1986;26:174-180.

$\checkmark 9$ Lee HS, Lee MS, Lee SM, Lee SY, et al: Histological grading of IgA nephropathy predicting renal outcome: revisiting H.S. Lee's glomerular grading system. Nephrol Dial Transplant 2005;20:342-348.

-10 Garcia Camin RM, Cabezas A, Calero F, Ballarin JA: Steroid-responsive nephrotic syndrome in IgA nephropathy (in Spanish). Nefrologia 2004;24(suppl 3):68-71.

11 Barratt J, Feehally J: IgA nephropathy. J Am Soc Nephrol 2005;16:2088-2097.

$\checkmark 12$ Bennett WM, Kincaid-Smith P: Macroscopic hematuria in mesangial IgA nephropathy: correlation with glomerular crescents and renal dysfunction. Kidney Int 1983;23:393400 .

13 Kincaid-Smith P, Bennett WM, Dowling JP, Ryan GB: Acute renal failure and tubular necrosis associated with hematuria due to glomerulonephritis. Clin Nephrol 1983;19:206210.

-14 Kincaid-Smith P, Ryan GB, Dowling JP, Nicholls K: Acute renal failure in mesangial IgA nephropathy. Contrib Nephrol 1984; 40:182-186.
15 Packham DK, Hewitson TD, Yan HD, Elliott CE, et al: Acute renal failure in IgA nephropathy. Clin Nephrol 1994;42:349-353.

16 Feith GW, Assmann KJ, Wetzels JF: Acute renal failure in patients with glomerular diseases: a consequence of tubular cell damage caused by haematuria? Neth J Med 2003;61: 146-150.

17 Praga M, Gutierrez-Millet V, Navas JJ, Ruilope LM, et al: Acute worsening of renal function during episodes of macroscopic hematuria in IgA nephropathy. Kidney Int 1985;28:69-74.

>18 Fogazzi GB, Imbasciati E, Moroni G, Scalia A, et al: Reversible acute renal failure from gross haematuria due to glomerulonephritis: not only in IgA nephropathy and not associated with intratubular obstruction. Nephrol Dial Transplant 1995;10:624-629.

19 Gutierrez E, Gonzalez E, Hernandez E, Morales E, et al: Factors that determine an incomplete recovery of renal function in macrohematuria-induced acute renal failure of IgA nephropathy. Clin J Am Soc Nephrol 2007;2:51-57.

20 Braun SR, Weiss FR, Keller AI, Ciccone JR, et al: Evaluation of the renal toxicity of heme proteins and their derivatives: a role in the genesis of acute tubule necrosis. J Exp Med 1970;131:443-460.

21 Zager RA, Foerder CA: Effects of inorganic iron and myoglobin on in vitro proximal tubular lipid peroxidation and cytotoxicity. J Clin Invest 1992;89:989-995.

22 Cleary CM, Moreno JA, Fernandez B, Ortiz A, et al: Glomerular haematuria, renal interstitial haemorrhage and acute kidney injury. Nephrol Dial Transplant 2010;25:41034106.

23 Pozzi C, Andrulli S, Del Vecchio L, Melis P, et al: Corticosteroid effectiveness in IgA nephropathy: long-term results of a randomized, controlled trial. J Am Soc Nephrol 2004;15:157-163.

24 Pozzi C, Bolasco PG, Fogazzi GB, Andrulli S, et al: Corticosteroids in IgA nephropathy: a randomised controlled trial. Lancet 1999; 353:883-887.

25 Mustonen J, Pasternack A, Rantala I: The nephrotic syndrome in IgA glomerulonephritis: response to corticosteroid therapy. Clin Nephrol 1983;20:172-176.

26 Sinnassamy P, O’Regan S: Mesangial IgA deposits with steroid responsive nephrotic syndrome: probable minimal lesion nephrosis. Am J Kidney Dis 1985;5:267-269.
-27 Hotta O, Furuta T, Chiba S, Tomioka S, et al: Regression of IgA nephropathy: a repeat biopsy study. Am J Kidney Dis 2002;39:493502 .

28 Cheng IK, Chan KW, Chan MK: Mesangial IgA nephropathy with steroid-responsive nephrotic syndrome: disappearance of mesangial IgA deposits following steroid-induced remission. Am J Kidney Dis 1989;14: 361-364.

-29 Reich HN, Troyanov S, Scholey JW, Cattran DC: Remission of proteinuria improves prognosis in IgA nephropathy. J Am Soc Nephrol 2007; 18:3177-3183.

30 Donadio JV, Bergstralh EJ, Grande JP, Rademcher DM: Proteinuria patterns and their association with subsequent end-stage renal disease in IgA nephropathy. Nephrol Dial Transplant 2002;17:1197-1203.

-31 Radford MG Jr, Donadio JV Jr, Bergstralh EJ, Grande JP: Predicting renal outcome in IgA nephropathy. J Am Soc Nephrol 1997;8:199207.

>32 Neelakantappa K, Gallo GR, Baldwin DS: Proteinuria in IgA nephropathy. Kidney Int 1988;33:716-721.

33 Bartosik LP, Lajoie G, Sugar L, Cattran DC: Predicting progression in IgA nephropathy. Am J Kidney Dis 2001;38:728-735.

>34 D’Amico G: Natural history of idiopathic IgA nephropathy and factors predictive of disease outcome. Semin Nephrol 2004;24: 179-196.

>35 de Groot K, Harper L, Jayne DR, Flores Suarez LF, et al: Pulse versus daily oral cyclophosphamide for induction of remission in antineutrophil cytoplasmic antibody-associated vasculitis: a randomized trial. Ann Intern Med 2009;150:670-680.

36 Ballardie FW, Roberts IS: Controlled prospective trial of prednisolone and cytotoxics in progressive IgA nephropathy. J Am Soc Nephrol 2002;13:142-148.

>37 Yamagata K, Takahashi H, Tomida C, Yamagata $\mathrm{Y}$, et al: Prognosis of asymptomatic hematuria and/or proteinuria in men. High prevalence of IgA nephropathy among proteinuric patients found in mass screening. Nephron 2002;91:34-42.

38 Briganti EM, Dowling J, Finlay M, Hill PA, et al: The incidence of biopsy-proven glomerulonephritis in Australia. Nephrol Dial Transplant 2001;16:1364-1367.

39 Rosenberg H: Primary nephropathy due to mesangial deposits of IgA (Berger's disease) (in Spanish) Rev Med Chile 1990;118:125133. 